Article

\title{
Dynamics of a Partially Confined, Vertical Upward-Fluid-Conveying, Slender Cantilever Pipe with Reverse External Flow
}

\author{
Xinbo Ge $\mathrm{e}^{1,2} \mathbb{D}$, Yinping $\mathrm{Li}^{1,2, *}$, Xiangsheng Chen ${ }^{1,2}$, Xilin Shi ${ }^{1,2, * \mathbb{C}}$, Hongling $\mathrm{Ma}^{1,2}$, \\ Hongwu Yin ${ }^{1,2}$, Nan Zhang ${ }^{3}$ and Chunhe Yang ${ }^{1,2}$ \\ 1 State Key Laboratory of Geomechanics and Geotechnical Engineering, Institute of Rock and Soil Mechanics, \\ Chinese Academy of Sciences, Wuhan 430071, China; gexinbo@163.com (X.G.); chenxs15@163.com (X.C.); \\ HonglingMa@outlook.com (H.M.); hong5yin@163.com (H.Y.); chyang@whrsm.ac.cn (C.Y.) \\ 2 University of Chinese Academy of Sciences, Beijing 100049, China \\ 3 State Key Laboratory of Coal Mine Disaster and Control, Chongqing University, Chongqing 400044, China; \\ zhangnan0032@foxmail.com \\ * Correspondence: ypli@whrsm.ac.cn (Y.L.); xlshi@whrsm.ac.cn (X.S.); Tel.: +86-027-8719-7469 (Y.L. \& X.S.)
}

Received: 18 February 2019; Accepted: 2 April 2019; Published: 4 April 2019

check for updates

\begin{abstract}
A linear theoretical model is established for the dynamics of a hanging vertical cantilevered pipe which is subjected concurrently to internal and reverse external axial flows. Such pipe systems may have instability by flutter (amplified oscillations) or static divergence (buckling). The pipe system under consideration is a slender flexible cantilevered pipe hanging concentrically within an inflexible external pipe of larger diameter. From the clamped end to the free end, fluid is injected through the annular passage between the external pipe and the cantilevered pipe. When exiting the annular passage, the fluid discharges in the counter direction along the cantilevered pipe. The inflexible external pipe has a variable length and it can cover a portion of the length of the cantilevered pipe. This pipe system has been applied in the solution mining and in the salt cavern underground energy storage industry. The planar motion equation of the system is solved by means of a Galerkin method, and Euler-Bernoulli beam eigenfunctions are used as comparison functions. Calculations are conducted to quantify the effects of different confinement conditions (i.e., the radial confinement degree of the annular passage and the confined-flow length) on the cantilevered pipe stability, for a long leaching-tubing-like system. For a long system, an increase in the radial confinement degree of the annular passage and the confined-flow length gives rise to a series of flutter and divergence. Additionally, the effect of the cantilevered pipe length is studied. Increasing the cantilevered pipe length results in an increase of the critical flow velocity while a decrease of the associated critical frequency. For a long enough system, the critical frequency almost disappears.
\end{abstract}

Keywords: salt cavern; leaching tubing; flutter instability; flow-induced vibration; internal and reverse external axial flows

\section{Introduction}

This paper focuses on flow-induced vibration of a slender flexible cantilevered pipe which is hanging concentrically inside a shorter inflexible external pipe, thus constituting an annular passage between the cantilevered pipe and the shorter external pipe, as shown in Figure 1. The entire pipe system is submerged in incompressible fluid and is placed within a closed cavity, with the upper portion outside the cavity. As shown in Figure 1a, from the fixed end to the free end of the shorter inflexible external pipe, fluid is injected as external flow into the closed cavity through the annular passage, and flows out as a free jet into stagnant fluid. In consideration of conservation of mass, initially 
stagnant fluid in the closed cavity is then forced through the cantilevered pipe, as a bounded reverse internal flow, discharging from the closed cavity upwards along the cantilevered pipe. Comparing the pipe configuration shown in Figure 1a with that given in Figure 1b, it is clear that the fluid flowing directions are opposite from each other. Contrary to the direction of fluid circulation illustrated in Figure 1a, fluid [1] is injected as internal flow into the closed cavity through the cantilever pipe and discharges through the annular passage, as shown in Figure $1 b$.
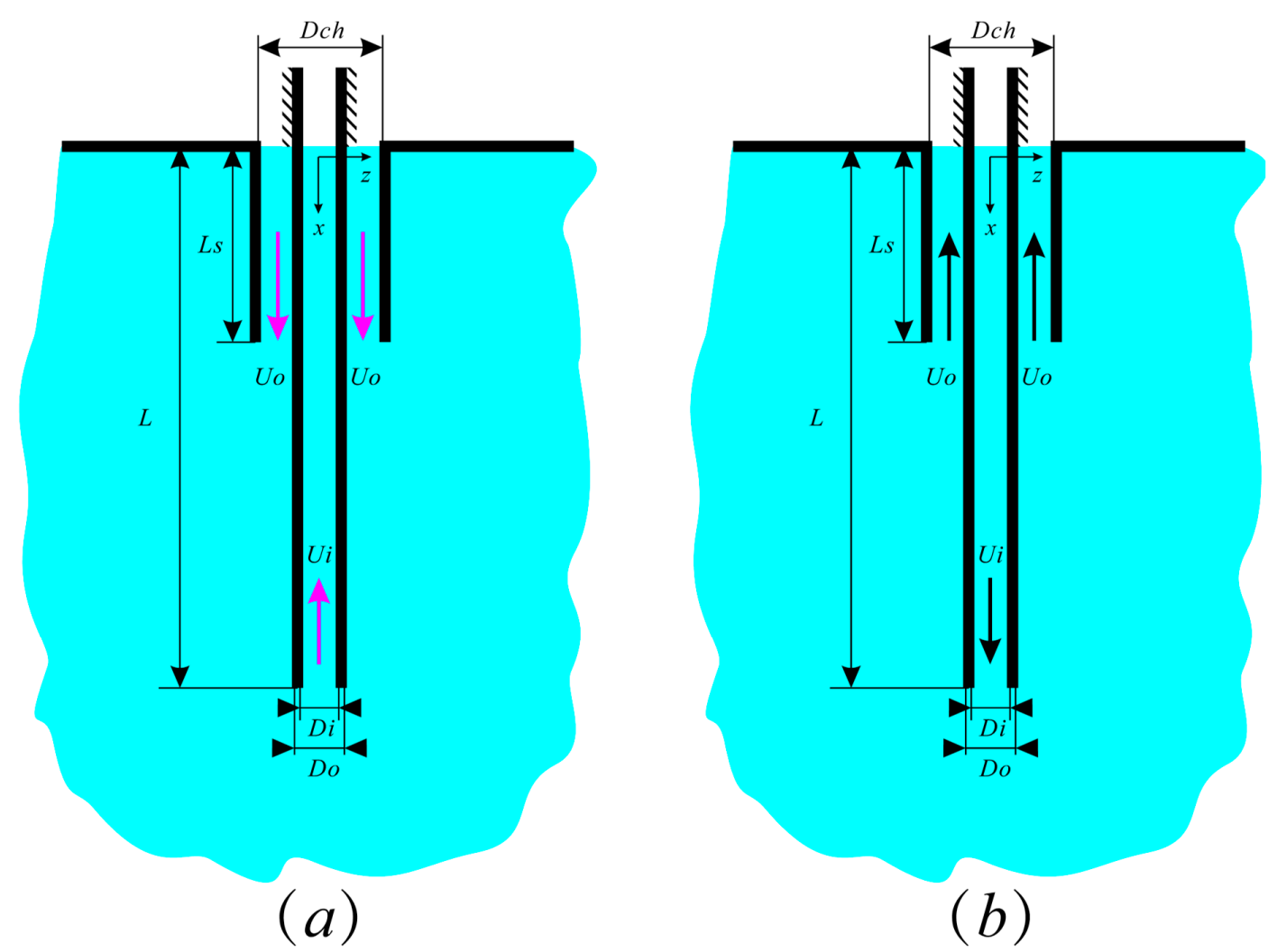

Figure 1. Schematic view of the pipe configuration. A hanging flexible cantilevered pipe conveying fluid is partially confined inside a shorter inflexible external pipe. (a) the system considered in this paper; (b) the system considered in [1].

The pipe configuration shown in Figure 1 has been applied in solution mining and in the salt cavern underground energy storage industry. Figure 2 shows the schematic view of pipe configurations applied in the salt cavern underground energy storage. Figure $2 \mathrm{a}, \mathrm{b}$ correspond to Figure $1 \mathrm{a}, \mathrm{b}$, respectively. In fact, the pipe failure or excessive bending caused by flow-induced vibrations is a well-known issue in the salt cavern storage industry [2,3]. For example, excessive bending of the inner tubing in a Chinese salt cavern storage is shown in Figure 3. This paper focuses on the pipe model shown in Figure 1a, and the motivation is desired to potentially improve the design of slender cantilever pipes in order to avoid issues cause by flow-induced vibration.

For several decades, a few researchers have been done the work on conveying-fluid pipes subjected simultaneously to both internal and external axial flows. Most of the work done involves concurrent flows, i.e., internal and external axial flows in the same direction. In [4], Cesari and Curioni investigated the buckling instability of pipes subjected to internal and external axial fluid flow. In [5], Hannoyer et al. investigated the dynamics and stability of both clamped-clamped cylindrical tubular beams conveying fluid, which simultaneously are subjected to independent axial external flows. They also studied the dynamics of cantilevered pipes fitted with a tapered nozzle at the free end. They provided theoretical and experimental results to support their model. In [6], Païdoussis and Besancon studied various aspects of the dynamic characteristic of clusters of tubular pipes which were 
subjected to internal flows and concurrently surrounded by bounded outer axial flows. To establish general characteristics of free motions, they obtained the eigenfrequencies of the system and studied their evolution by increasing either external or internal flows. In [7], Wang and Bloom established a mathematical model to investigate the vibration and stability of a submerged and inclined concentric pipe system which subjected to internal and external flow, and obtained the resonant frequencies of the system. In [8], Païdoussis et al. developed a theoretical model to study the vibration of a hanging tubular cantilever which was centrally inside a cylindrical container, with fluid flowing within the cantilever, and discharging from the free end. The configuration thus resembles that of a drill-string with a floating fluid-powered drill-bit. Of particular interest is the study in [1]. Moditis and Païdoussis preliminarily discussed the dynamics of the pipe configuration shown in Figure 1b. Furthermore, they developed a theoretical model and carried out corresponding experiments.

Because the length of the cantilevered pipe system in practical applications is on the order of one kilometer, how the system behavior evolves is of interest as the length increases. Theoretical and experimental studies $[9,10]$ regarding long hanging vertical pipes conveying fluid have shown that both the critical flow velocity and associated frequency for instability tend to be asymptotic toward different limiting values with increasing the length of the pipes. The literature related to aspirating cantilevered pipes was believed to be useful for analyzing the dynamics of a vertical hanging pipe shown in Figure 1a. For example, in [11,12], the authors theoretically and experimentally considered the dynamic stability of a submerged cantilever pipe aspirating fluid, which could be applied in deep ocean mining.

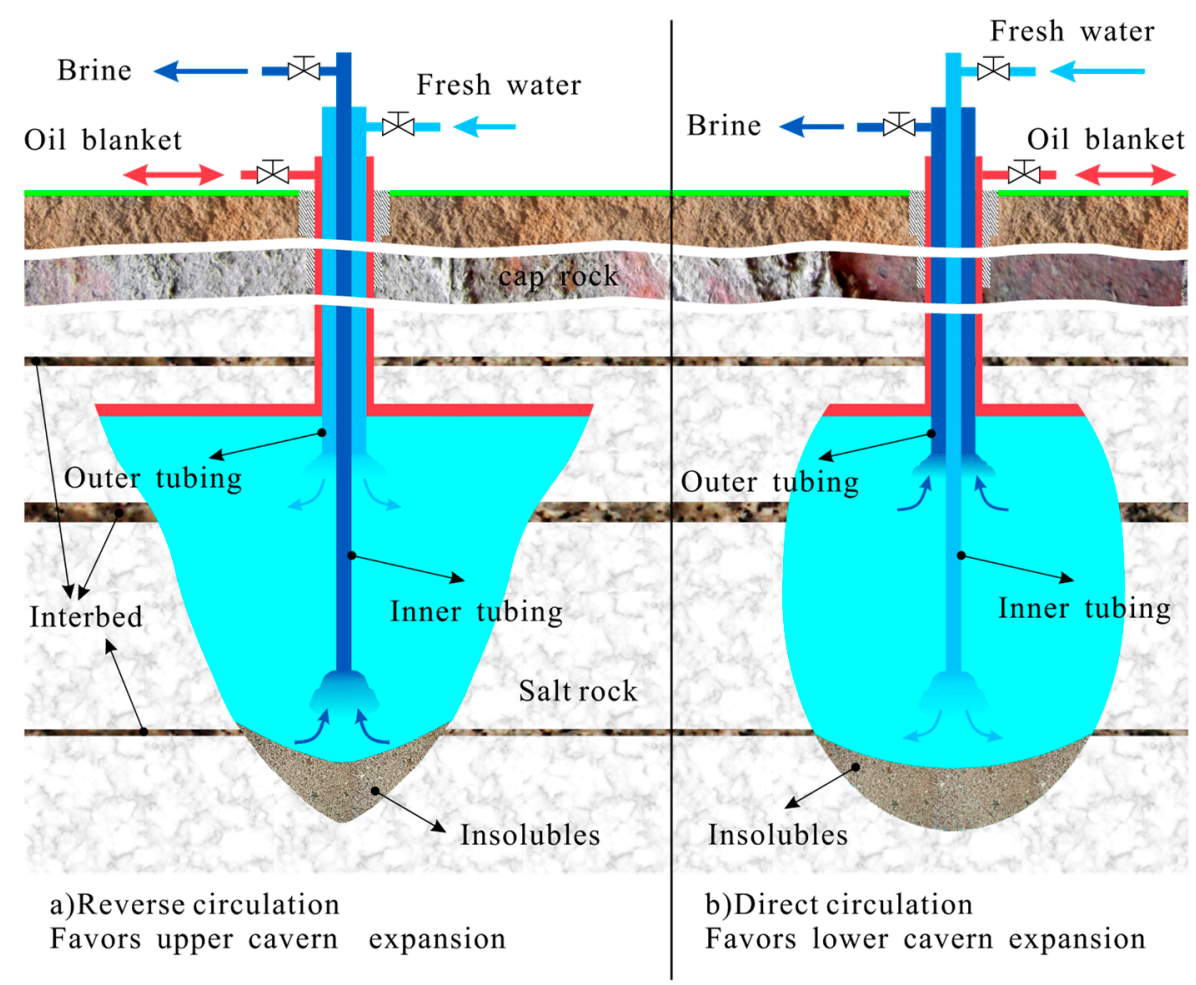

Figure 2. Schematic view of the salt cavern underground energy storage application. Fresh water or light brine is injected into the inner tubing, and high-concentration brine is expelled through the annular space in between the inner and outer tubings. This process is known as direct circulation, as distinguished from reverse circulation. Direct and reverse circulations are alternately employed until the salt cavern achieves the design shape and dimensions. 


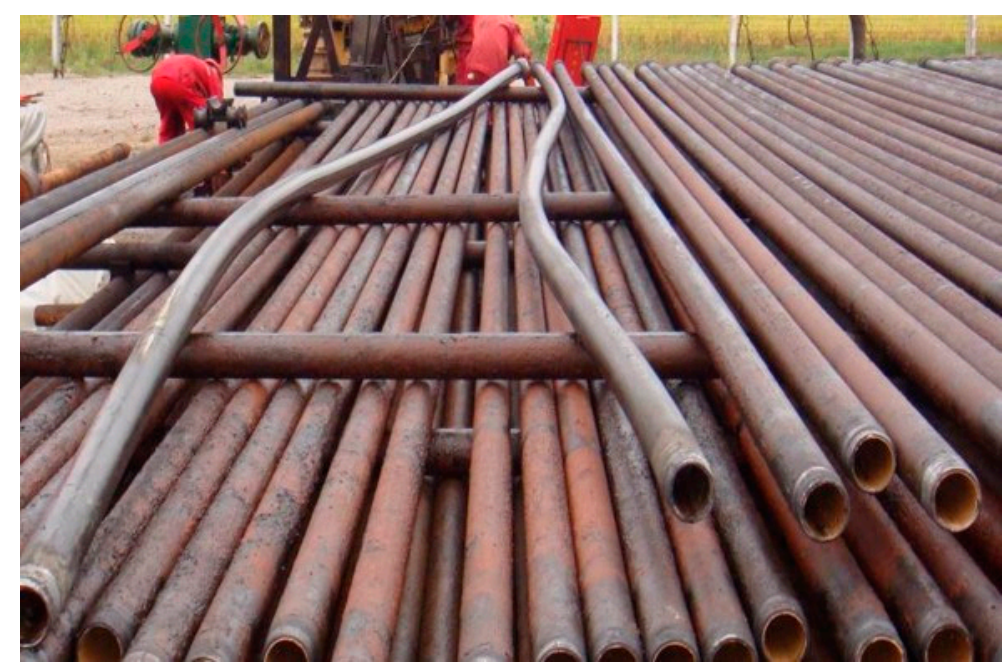

Figure 3. Excessive bending of the inner tubing at a Chinese salt cavern storage [3].

Several key dimensions of the system under consideration are defined in Figure 1a. The $x$-axis lies in the undeflected centerline of the internal cantilever pipe, while the $z$-axis lies along the lateral direction and is perpendicular to the $x$-axis. $L$ is the length of the cantilever pipe, while $L_{s}$ is the length of the shorter inflexible external pipe (i.e. the length of the annular passage). $U_{i}$ is the internal flow velocity (area average flow velocity) inside the cantilevered pipe, and $U_{o}$ is the external flow velocity (area average flow velocity) in the annular passage with reference to the cantilever pipe.

Firstly, the present paper studies the linear idealized system shown in Figure 1a. We present a derivation of a theoretical model as well as a method of solving it are discussed. Secondly, we give theoretical results for slender leaching-tubing-like systems which are associated with the industrial application of salt cavern storage. We also obtained some unexpected and interesting results by numerical simulation. Finally, we present general conclusions.

\section{Problem Formulation}

\subsection{Derivation of the Motion Equation of Theoretical Model}

The derivation of the linear theoretical model is carried out as follows. Take a small element of length $\delta x$ of the cantilevered pipe into consideration, as shown in Figure 4a, under the action of fluid-related and structural forces and moments. Force balances in the $x$ - and $z$-directions renders, respectively

$$
\begin{gathered}
\frac{\partial F_{T}}{\partial x}-\frac{\partial}{\partial x}\left(Q \frac{\partial w}{\partial x}\right)+M_{p} g-F_{i t}+F_{e t}-\left(F_{i n}+F_{e n}\right) \frac{\partial w}{\partial x}=0 \\
\frac{\partial Q}{\partial x}+\frac{\partial}{\partial x}\left(F_{T} \frac{\partial w}{\partial x}\right)+F_{i n}+F_{e n}+\left(F_{e t}-F_{i t}\right) \frac{\partial w}{\partial x}-M_{p} \frac{\partial^{2} w}{\partial t^{2}}=0
\end{gathered}
$$

where $w$ is the lateral deflection; $F_{T}$ is the axial tension; $M_{p}$ is the mass per unit length of the cantilever pipe; $Q$ is the transverse shear force in the cantilevered pipe; $g$ is the gravitational acceleration; $F_{i n}$ and $F_{i t}$ are the normal and tangential hydrodynamic forces because of the internal flow $U_{i}$, respectively; $F_{e n}$ and $F_{e t}$ are the normal and tangential hydrodynamic forces because of the external flow, respectively. 


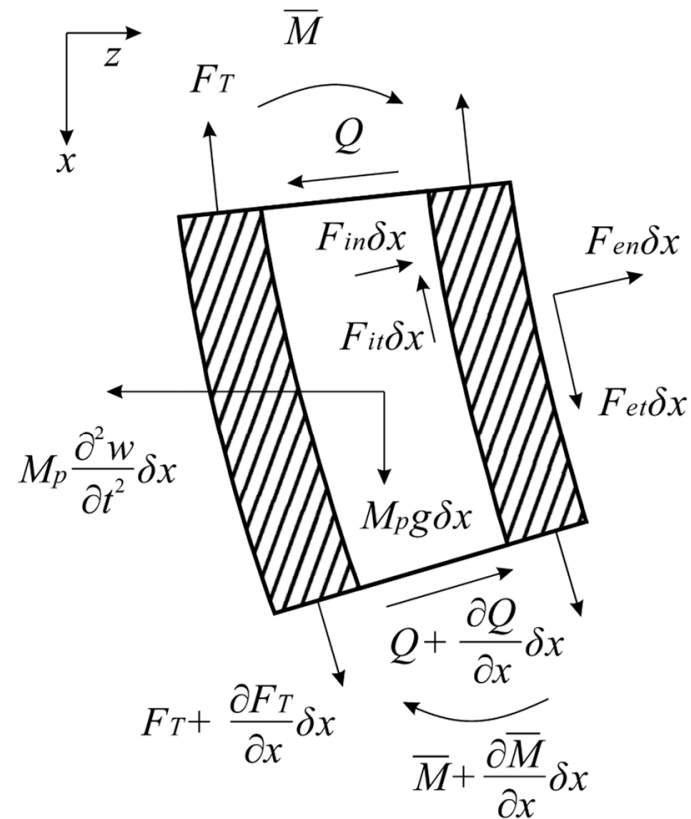

(a)

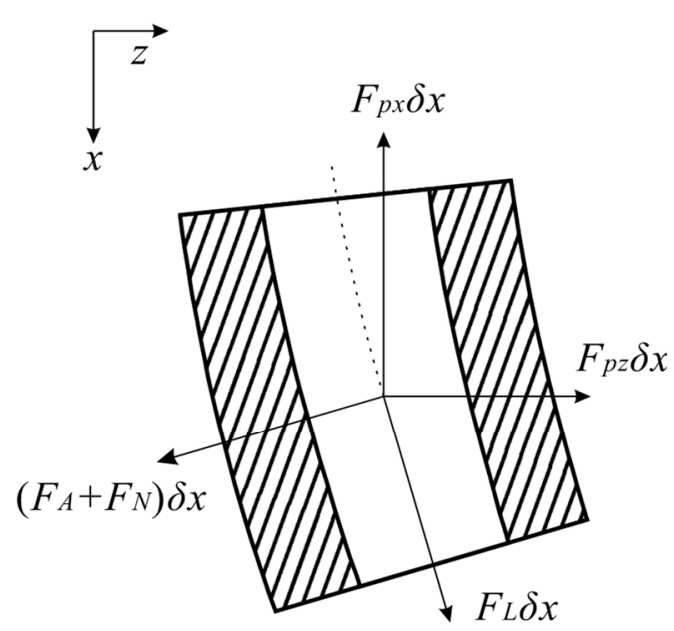

$(b)$

Figure 4. (a) Forces acting on an element of length $\delta x$ of the cantilevered pipe. (b) Forces due to the outside fluid acting on an element $\delta x$ of the cantilevered pipe.

As approximated by the Euler-Bernoulli (E-B) beam theory, one obtains the following relationship

$$
Q=-\frac{\partial}{\partial x}\left(E I \frac{\partial^{2} w}{\partial x^{2}}\right)
$$

where $E I$ is the flexural rigidity. Internal dissipation in the cantilevered pipe material is relatively small compared to dissipation by the surrounding fluid so it can be neglected [13]. Substituting Equation (3) into Equations (1) and (2), and neglecting second-order terms, one finds the following expressions in the $x$ - and $z$-directions, respectively

$$
\begin{gathered}
\frac{\partial F_{T}}{\partial x}-\left(F_{i t}+F_{i n} \frac{\partial w}{\partial x}\right)+\left(F_{e t}-F_{e n} \frac{\partial w}{\partial x}\right)+M_{p} g=0 \\
E I \frac{\partial^{4} w}{\partial x^{4}}-\frac{\partial}{\partial x}\left(F_{T} \frac{\partial w}{\partial x}\right)-\left(F_{i n}-F_{i t} \frac{\partial w}{\partial x}\right)-\left(F_{e n}+F_{e t} \frac{\partial w}{\partial x}\right)+M_{p} \frac{\partial^{2} w}{\partial t^{2}}=0
\end{gathered}
$$

The $F_{i n}$ and $F_{i t}$ (hydrodynamic forces because of internal flow) are obtained by a force balance on an element $\delta x$ of internal fluid (Figure 5b) in the manner of Païdoussis [14,15]. The $F_{i n}{ }^{\prime}$ and $F_{i t}{ }^{\prime}$ in Figure $5 \mathrm{~b}$ are a pair of interaction forces with the $F_{i n}$ and $F_{i t}$ in Figure $4 \mathrm{a}, F_{i n}{ }^{\prime}=-F_{\text {in }}$ and $F_{i t}{ }^{\prime}=-F_{i t}$. The resulting expressions are written as below in the $x$ - and $z$-directions, respectively,

$$
F_{i t}+F_{i n} \frac{\partial w}{\partial x}=-M_{f} g+A_{f} \frac{\partial p_{i}}{\partial x}
$$

and

$$
F_{i n}-F_{i t} \frac{\partial w}{\partial x}=-M_{f}\left(\frac{\partial^{2} w}{\partial t^{2}}-2 U_{i} \frac{\partial^{2} w}{\partial x \partial t}+U_{i}^{2} \frac{\partial^{2} w}{\partial x^{2}}\right)-A_{f} \frac{\partial}{\partial x}\left(p_{i} \frac{\partial w}{\partial x}\right)
$$

where $M_{f}$ is the mass of internal fluid per unit length; $p_{i}$ is the internal pressure in the cantilevered pipe; $A_{f}$ is the cross-sectional area of the internal flow, and $M_{f}=\rho_{f} A_{f}$, in which $\rho_{f}$ is the fluid density. 

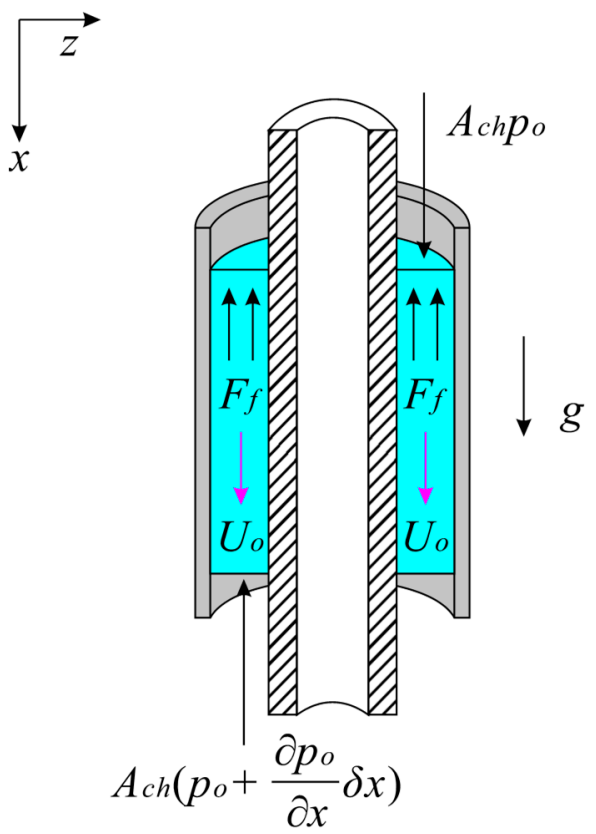

(a)

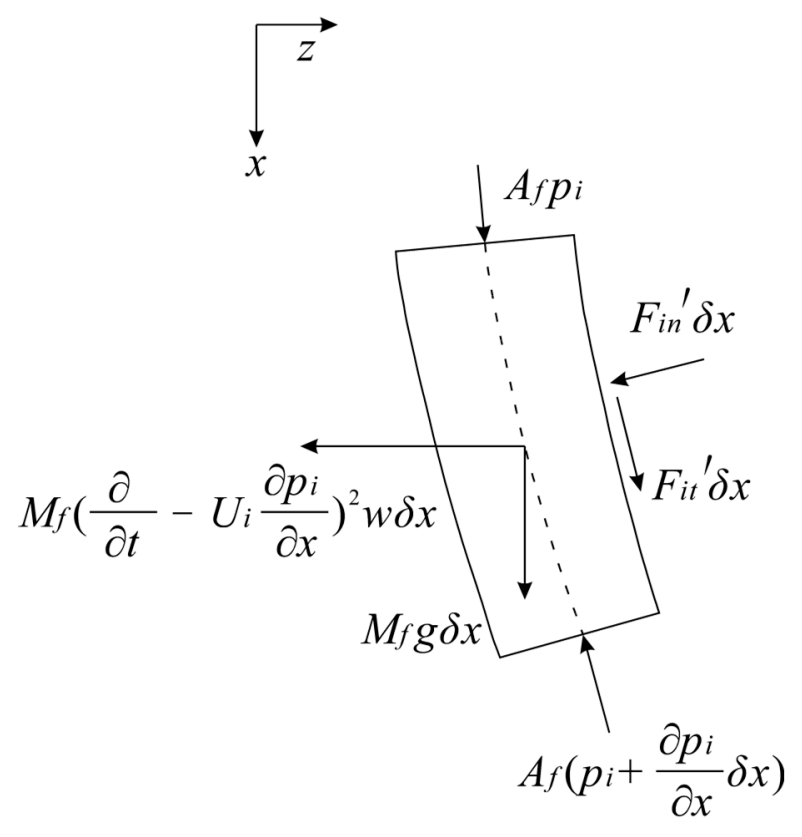

(b)

Figure 5. (a) Forces acting on an element of length $\delta x$ of the annular flow. (b) Forces acting on an element $\delta x$ of the internal flow.

Substituting Equations (6) and (7) in (4) and (5) renders the following equations in the $x$ - and $z$-directions, respectively

$$
\begin{gathered}
\frac{\partial F_{T}}{\partial x}+\left(M_{f} g-A_{f} \frac{\partial p_{i}}{\partial x}\right)+\left(F_{e t}-F_{e n} \frac{\partial w}{\partial x}\right)+M_{p} g=0 \\
E I \frac{\partial^{4} w}{\partial x^{4}}-\frac{\partial}{\partial x}\left(F_{T} \frac{\partial w}{\partial x}\right)+\left[M_{f}\left(\frac{\partial^{2} w}{\partial t^{2}}-2 U_{i} \frac{\partial^{2} w}{\partial x \partial t}+U_{i}^{2} \frac{\partial^{2} w}{\partial x^{2}}\right)+A_{f} \frac{\partial}{\partial x}\left(p_{i} \frac{\partial w}{\partial x}\right)\right]-\left(F_{e n}+F_{e t} \frac{\partial w}{\partial x}\right)+M_{p} \frac{\partial^{2} w}{\partial t^{2}}=0
\end{gathered}
$$

The field of flow outside the cantilevered pipe can be simplified because the cantilever pipe displacements $w$ are considered to be small according to E-B beam theory. More specifically, the external flow is modelled as the superposition of a perturbation potential because of the cantilever pipe vibrations in the mean axial flow $[15,16]$. Hence, the effects of fluid viscosity are considered to be different from this potential flow, and the viscosity-related forces are added separately to the system. When linear investigations of fluid-structure interaction issues are carried out, this is a common approach. There are more details in $[5,15]$.

The resultant force of all external hydrodynamic forces acting on the cantilevered pipe (Figure 4a) can be broken down into $F_{e n}$ and $F_{e t}$ in the directions perpendicular and tangential to the cantilever pipe centerline, respectively. Projection of the external hydrodynamic force in the $x$ - and $z$-directions yields the following force-balance equations

$$
F_{e t}-F_{e n} \frac{\partial w}{\partial x}=F_{L}-F_{p x}
$$

and

$$
F_{e n}+F_{e t} \frac{\partial w}{\partial x}=-\left(F_{A}+F_{N}\right)+F_{p z}+F_{L} \frac{\partial w}{\partial x} .
$$

In Equations (10) and (11), $F_{A}$ is the lateral inviscid hydrodynamic force; $F_{p x}$ and $F_{p z}$ are the resultant forces due to external pressure in the $x$ and $z$ directions, respectively; $F_{N}$ and $F_{L}$ are the fluid frictional viscous forces perpendicular and tangential to the cantilever pipe centerline, respectively; and high-order terms have been omitted. 
The added (hydrodynamic) mass $M_{a}$ is the mass per unit length for the annular (external) fluid associated with motions of the cantilevered pipe. Based on the perturbation potential, for a thin boundary layer, the added (hydrodynamic) mass $M_{a}=\chi \rho_{f} A_{o}[17,18]$, where $A_{o}=\pi D_{o}{ }^{2} / 4$ is the external cross-sectional area of the cantilevered pipe. The parameter $\chi$ quantifies the effect of radial confinement degree (or narrowness) of the annular flow passage as

$$
\chi=\frac{\left(D_{c h} / D_{o}\right)^{2}+1}{\left(D_{c h} / D_{o}\right)^{2}-1} \lim _{D_{c h} \rightarrow \infty}(\chi)=\lim _{D_{c h} \rightarrow \infty} \frac{\left(D_{c h} / D_{o}\right)^{2}+1}{\left(D_{c h} / D_{o}\right)^{2}-1}=1 .
$$

In Equation (12), $D_{c h}$ is the inner diameter of the passage (the inflexible external pipe) and $D_{o}$ is the outer diameter of the cantilever pipe as shown in Figure 1. Regarding an unconfined pipe, $D_{c h} \rightarrow \infty$ and as a result $M_{a}$ is equal to $\rho_{f} A_{o}$, i.e., the displaced mass of the fluid per unit length. Hence, considering the variation of confinement along the cantilevered pipe, the added (hydrodynamic) mass may be written as

$$
M_{a}=\left[\chi+(1-\chi) H\left(x-L_{s}\right)\right] \rho_{f} A_{o}
$$

where $\chi$ pertains to the confined portion of the cantilevered pipe, $0 \leq x \leq L_{s}$, and $H\left(x-L_{s}\right)$ is the Heaviside step function.

As is shown in Figure $1 \mathrm{a}$, both the external flow velocity $U_{o}$ and the confinement degree vary along the length of the cantilevered pipe. For the sake of simplicity, it is assumed that $U_{0}$ is zero along the unconfined part, $L_{S}<x \leq L$, and immediately attains the value of $U_{o}$ along the confined portion of the cantilevered pipe, $0 \leq x<L_{s}$. The above assumptions can also be found in the literature [1]. Thus, the lateral inviscid hydrodynamic force $F_{A}$ can be written as

$$
F_{A}=\left(\frac{\partial}{\partial t}+U_{o} \frac{\partial}{\partial x}-U_{o} H\left(x-L_{s}\right) \frac{\partial}{\partial x}\right)\left\{\left[\chi+(1-\chi) H\left(x-L_{s}\right)\right] \rho_{f} A_{o}\left(\frac{\partial w}{\partial t}+U_{o} \frac{\partial w}{\partial x}-U_{o} H\left(x-L_{s}\right) \frac{\partial w}{\partial x}\right)\right\},
$$

where the initial expression [16] and later [17] have been altered to explicate the spatial variation of both the external flow velocity and the added (hydrodynamic) mass Equation (13). After various simplifications, the formula given in Equation (14) was arrived at

$$
F_{A}=(1-\chi) \rho_{f} A_{o} H\left(x-L_{s} \frac{\partial^{2} w}{\partial t^{2}}+\rho_{f} A_{o} \chi \frac{\partial^{2} w}{\partial t^{2}}-2 A_{o} U_{o} \rho_{f} \chi H\left(x-L_{s}\right) \frac{\partial^{2} w}{\partial x \partial t}+2 A_{o} U_{o} \rho_{f} \chi \frac{\partial^{2} w}{\partial x \partial t}-A_{o} U_{o}^{2} \rho_{f} \chi H\left(x-L_{s}\right) \frac{\partial^{2} w}{\partial x^{2}}+A_{o} U_{o}^{2} \rho_{f} \chi \frac{\partial^{2} w}{\partial x^{2}}\right.
$$

The fluid frictional viscous force $F_{L}$ tangential to the cantilevered pipe centerline is

$$
F_{L}=\frac{1}{2} C_{f} \rho_{f} D_{o} U_{o}^{2}\left[1-H\left(x-L_{s}\right)\right]
$$

where $C_{f}$ is the frictional damping coefficient, with a value of 0.0125 to give an acceptable estimate of the fluid frictional viscous force $F_{L}$ [8].

Equation (16) was modified from the literature [17] to take the spatial variation of the mean external flow velocity into account. Likewise, in terms of the literature [17], the fluid frictional viscous force $F_{N}$ perpendicular to the cantilevered pipe centerline is

$$
F_{N}=\frac{1}{2} C_{f} \rho_{f} D_{o} U_{o}\left[1-H\left(x-L_{s}\right)\right]\left\{\frac{\partial w}{\partial t}+\left[1-H\left(x-L_{s}\right)\right] U_{o} \frac{\partial w}{\partial x}\right\}+k \frac{\partial w}{\partial t},
$$

where the variation of the external flow velocity $U_{o}$ has been taken into account; $k$ is a viscous damping coefficient which only relates to lateral motions of the cantilever pipe, without average external flow $U_{0}$. Based on two-dimensional flow analysis, expressions used for $k$ are derived in $[13,18]$. For a thin boundary layer, the coefficient $k$ is calculated via the following expression

$$
k=\frac{2 \sqrt{2}}{\sqrt{S}} \frac{1+\bar{\gamma}^{3}}{\left(1-\bar{\gamma}^{2}\right)^{2}} \rho_{f} A_{o} \Re\{\Omega\}
$$


In (10), $S=\mathrm{R}\{\Omega\} D_{o}^{2} /(4 v)$ represents the oscillatory Reynolds number (i.e., Stokes number), where $v$ and $\mathrm{R}\{\Omega\}$ are the kinematic viscosity of the fluid and the circular frequency of oscillation, respectively; $\bar{\gamma}=D_{o} / D_{c h}$ is a measure of the radial confinement degree of the annular passage. Naturally, based on Figure $1 \mathrm{a}$, the value of $k$ varies along the cantilevered pipe. This variation of $k$ is explained by letting

$$
\begin{gathered}
F_{N}=\frac{1}{2} C_{f} \rho_{f} D_{o} U_{o}\left\{\left[1-H\left(x-L_{s}\right)\right] \frac{\partial w}{\partial t}+\left[1-H\left(x-L_{s}\right)\right] U_{o} \frac{\partial w}{\partial x}\right\}+k_{u}\left[\frac{1+\bar{\gamma}^{3}}{\left(1-\bar{\gamma}^{2}\right)^{2}}+H\left(x-L_{s}\right)\left(1-\frac{1+\bar{\gamma}^{3}}{\left(1-\bar{\gamma}^{2}\right)^{2}}\right)\right] \frac{\partial w}{\partial t} . \\
k_{u}=\frac{2 \sqrt{2}}{\sqrt{S}} \rho_{f} A_{o} \Re\{\Omega\}
\end{gathered}
$$

In (19) and (20), $k_{u}$ represents the friction coefficient applicable to the cantilevered pipe without confined portion, $L_{S}<x \leq L$.

Finally, the forces $\left(F_{p x}\right.$ and $F_{p z}$ ) caused by mean tensioning (induced by gravity) and pressurization are considered, respectively. $F_{p x}$ and $F_{p z}$ are cleverly derived in $[15,17]$ and they are expressed as

$$
F_{p x}=-\frac{\partial}{\partial x}\left(A_{o} p_{o}\right)+A_{o} \frac{\partial p_{o}}{\partial x}
$$

and

$$
F_{p z}=A_{o} \frac{\partial}{\partial x}\left(p_{o} \frac{\partial w}{\partial x}\right)
$$

in the $x$ - and $z$-directions respectively, where $p_{0}$ represents the fluid pressure outside the cantilevered pipe.

For the purpose of analyzing the model shown in Figure 1a, the outlet effects of the flow exiting from the annular passage have been reduced to a tinily thin region at $x=L_{s}$. For $0 \leq x<L_{s}$, there is a pressure loss due to the friction of the flowing fluid inside the annulus, while there is a pressure increasing due to the gravity. For $L_{s}<x \leq L$, there is a purely hydrostatic pressure distribution along the unconfined portion of the cantilever pipe. For $0 \leq x<L_{s}$, an annular fluid element (i.e., the external flow of length $\delta x$ ) (Figure 5a) is considered, and a force balance per unit length is obtained as

$$
-A_{c h} \frac{\partial p_{o}}{\partial x}-F_{f}+A_{c h} \rho_{f} g=0,
$$

where $A_{c h}=\pi\left(D_{c h}{ }^{2}-D_{o}{ }^{2}\right) / 4$ represents the cross-sectional flow area of the annular passage; $F_{f}$ represents the total wall-friction force acting on the fluid element.

It is assumed that an equal wall shear stress acts on both annular passage surfaces, the total wall-friction force $F_{f}$ can be expressed as

$$
\frac{F_{f}}{S_{t o t}}=\frac{F_{L}}{S_{0}}
$$

in which $S_{t o t}=\pi\left(D_{c h}+D_{o}\right)$ is the total wetted area of the annular flow per unit length, and $S_{o}$ is the outside wetted pipe perimeter.

Combining Equations (23) and (24), multiplied by $\left(A_{o} / A_{c h}\right)$, the resultant equation is rearranged as

$$
A_{o} \frac{\partial p_{o}}{\partial x}=-F_{L}\left(\frac{D_{o}}{D_{h}}\right)+A_{o} \rho_{f} g
$$

where $D_{h}=4 A_{c h} / S_{t o t}=\left(D_{c h}-D_{o}\right)$ is the hydraulic diameter of the external flow in the annular passage. Integration of Equation (25), where for the confined portion external fluid pressure at $x=0$ is the reference pressure $\left(\left.p_{0}\right|_{x=0}=0\right)$, with respect to $x$ gives

$$
p_{o}(x)=\left[-\frac{F_{L}}{A_{o}}\left(\frac{D_{o}}{D_{h}}\right)+\rho_{f} g\right] x
$$


for $0 \leq x<L_{s}$.

For the unconfined part, i.e., $L_{s}<x \leq L$, the external fluid pressure distribution is hydrostatic

$$
\frac{\partial p_{o}}{\partial x}=\rho_{f} g
$$

which upon integration results in

$$
p_{o}(x)=\rho_{f} g x+C_{1}
$$

in which $C_{1}$ is an integration constant determined in the following description.

It is assumed that $x_{1}=L_{s}{ }^{-}$is the axial location just inside the annular passage, and $x_{2}=L_{s}{ }^{+}$is the location just outside the annular passage. Based on Bernoulli's equation, an energy balance of the fluid is obtained from $x_{1}$ to $x_{2}$

$$
\left.p_{o}\right|_{x_{2}}=\left.p_{o}\right|_{x_{1}}+\frac{1}{2} \rho_{f} U_{o}^{2}-\rho_{f} g h_{e}, h_{e}=\frac{K_{1} U_{o}^{2}}{2}
$$

where the quantity $h_{e}$, with $K_{1}=1$, is the head-loss associated with sudden enlargement of the external flow in the annular passage into the surrounding fluid at $x=L_{s}{ }^{+}$[19]. Combination Equations (28) and (29) yields

$$
C_{1}=\left[-\frac{\left\|F_{L}\right\|}{A_{o}}\left(\frac{D_{o}}{D_{h}}\right) L_{s}\right]+\frac{1}{2} \rho_{f} U_{o}^{2}-\rho_{f} g h_{e},
$$

in which ||$F_{L}||=0.5 \rho_{f} C_{f} D_{o} U_{o}^{2}$.

Through the above analysis, the resulting fluid pressure gradient and fluid pressure distribution over the whole cantilevered pipe, for $0 \leq x \leq L$, are, respectively

$$
\frac{\partial p_{o}}{\partial x}=-\frac{\left\|F_{L}\right\|}{A_{o}}\left(\frac{D_{o}}{D_{h}}\right)\left[1-H\left(x-L_{s}\right)\right]+\rho_{f} g+\left(\frac{1}{2} \rho_{f} U_{o}^{2}-\rho_{f} g h_{e}\right) \delta_{D}\left(x-L_{s}\right)
$$

and

$$
p_{o}=-\frac{\left\|F_{L}\right\|}{A_{o}}\left(\frac{D_{o}}{D_{h}}\right) x+\frac{\left\|F_{L}\right\|}{A_{o}}\left(\frac{D_{o}}{D_{h}}\right)\left(x-L_{s}\right) H\left(x-L_{s}\right)+\rho_{f} g x+\left(\frac{1}{2} \rho_{f} U_{o}^{2}-\rho_{f} g h_{e}\right) H\left(x-L_{s}\right),
$$

where $\delta_{D}\left(x-L_{s}\right)$ is the Dirac delta function.

Substituting Equations (16) and (21) in (10), and subsequently substituting (10) into (8), the force balance on the cantilevered pipe is obtained in the $x$-direction, namely

$$
\frac{\partial}{\partial x}\left(F_{T}-A_{f} p_{i}+A_{o} p_{o}\right)+M_{p} g+\rho_{f} A_{f} g-A_{o} \frac{\partial p_{o}}{\partial x}+\frac{1}{2} C_{f} \rho_{f} D_{o} U_{o}^{2}\left[1-H\left(x-L_{s}\right)\right]=0
$$

Substituting Equations (15), (16), (19), and (22) in (11), and subsequently substituting the result in (1), the motion equation is obtained in the $z$-direction,

$$
\begin{aligned}
& E I \frac{\partial^{4} w}{\partial x^{4}}-\frac{\partial}{\partial x}\left[\left(F_{T}-A_{f} p_{i}+A_{o} p_{o}\right) \frac{\partial w}{\partial x}\right]+M_{p} \frac{\partial^{2} w}{\partial \partial^{2}}+\left[M_{f}\left(\frac{\partial^{2} w}{\partial \partial^{2}}-2 U_{i} \frac{\partial^{2} w}{\partial x t}+U_{i}^{2} \frac{\partial^{2} w}{\partial x^{2}}\right)\right]+(1-\chi) \rho_{f} A_{o} H\left(x-L_{s}\right) \frac{\partial^{2} w}{\partial x^{2}}+\rho_{f} A_{o} \chi \frac{\partial^{2} w}{\partial t^{2}} \\
& -2 A_{o} U_{o} \rho_{f} \chi H\left(x-L_{s}\right) \frac{\partial^{2} w}{\partial x \partial t}+2 A_{o} U_{o} \rho_{f} \chi \frac{\partial^{2} w}{\partial x t}-A_{o} U_{o}^{2} \rho_{f} \chi H\left(x-L_{s}\right) \frac{\partial^{2} w}{\partial x^{2}}+A_{o} U_{o}^{2} \rho_{f} \chi \frac{\partial^{2} w}{\partial x^{2}}+\frac{1}{2} C_{f} \rho_{f} D_{0} U_{o}\left[1-H\left(x-L_{s}\right)\right] \frac{\partial w}{\partial t} \\
& +k_{u}\left[\frac{1+\bar{\gamma}^{3}}{\left(1-\bar{\gamma}^{2}\right)^{2}}+H\left(x-L_{s}\right)\left(1-\frac{1+\bar{\gamma}^{3}}{\left(1-\bar{\gamma}^{2}\right)^{2}}\right)\right] \frac{\partial w}{\partial t}=0 .
\end{aligned}
$$

In Equation (34), the tensioning and pressurization term $\left(F_{T}-p_{i} A_{f}+A_{o} p_{o}\right)$ is determined by integrating Equation (33) from $x$ to $L$, which yields

$$
\begin{aligned}
\left(F_{T}-A_{f} p_{i}+A_{o} p_{o}\right)= & \frac{1}{2} C_{f} \rho_{f} D_{o} U_{o}^{2}\left(\frac{D_{o}}{D_{h}}+1\right)\left(L_{S}-x\right)\left[1-H\left(x-L_{s}\right)\right]-A_{o}\left(\frac{1}{2} \rho_{f} U_{o}^{2}-\rho_{f} g h_{e}\right)\left[1-H\left(x-L_{s}\right)\right] \\
& +\left(M_{p} g+\rho_{f} A_{f} g-A_{o} \rho_{f} g\right)(L-x)+\left.\left(F_{T}-A_{f} p_{i}+A_{o} p_{o}\right)\right|_{L} .
\end{aligned}
$$

In Equation (35) $\left.\right|_{L}$ represents an evaluation of the term in parentheses at $x=L$. 
Hence, the final form of the motion equation is obtained in the $z$-direction by substituting Equation (35) in (34), as follows

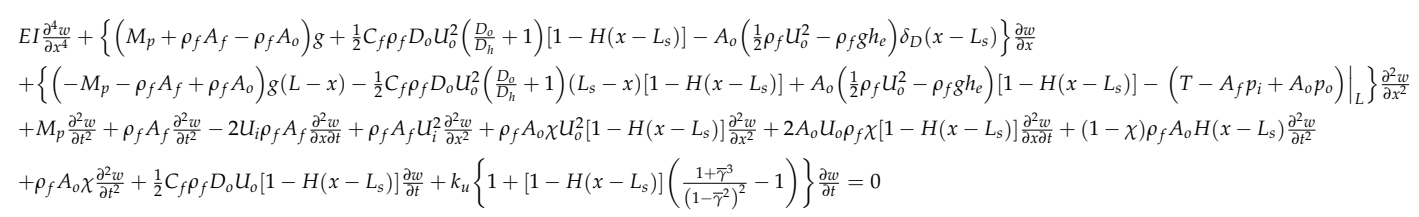

According to the Bernoulli equation, the pressures $\left.P_{o}\right|_{L}$ and $\left.P_{i}\right|_{L}$ are related to the energy balance of the fluid at $x=L$

$$
\left.p_{i}\right|_{L}=\left.p_{o}\right|_{L}-\frac{1}{2} \rho_{f} U_{i}^{2}-\rho_{f} g h_{a}, \quad h_{a}=\frac{K_{2} U_{i}^{2}}{2} .
$$

In Equation (37), the quantity $h_{a}$ is the headloss due to the stagnant fluid entering the cantilevered pipe at $x=L$ and acquiring internal flow velocity $U_{i}$, calculated with $0.8 \leq K_{2} \leq 0.9$, independent of flow velocity [19]. Consequently, evaluation of Equation (32) at $x=L$ yields $\left.P_{o}\right|_{L}$

$$
\left.p_{o}\right|_{L}=\frac{1}{2 A_{o}} C_{f} \rho_{f} D_{o} U_{o}^{2}\left(\frac{D_{o}}{D_{h}}\right) L^{\prime}+\rho_{f} g L+\frac{1}{2} \rho_{f} U_{o}^{2}-\rho_{f} g h_{a} .
$$

Finally, the internal and external flow velocities are related through conservation of mass, i.e., $U_{i} A_{f}=U_{0} A_{c h}$, which after some transformation is expressed as

$$
U_{o}=U_{i} \frac{D_{i}^{2}}{D_{c h}^{2}-D_{o}^{2}}
$$

\subsection{Boundary Conditions}

The motion Equation (36) is subjected to the boundary conditions

$$
w(0, t)=\left.\frac{\partial w}{\partial x}\right|_{x=0}=0,\left.\quad \frac{\partial^{2} w}{\partial x^{2}}\right|_{x=L}=\left.\frac{\partial^{3} w}{\partial x^{3}}\right|_{x=L}=0 .
$$

\subsection{Dimensionless Motion Equation and Boundary Conditions}

The motion Equation (36) is non-dimensionalized using the following dimensionless quantities

$$
\begin{aligned}
& \xi=\frac{x}{L}, \quad \tau=\left[\frac{E I}{M_{p}+\rho_{f} A_{f}+\rho_{f} A_{o}}\right]^{\frac{1}{2}} \frac{t}{L^{2}}, \quad \eta=\frac{w}{L}, \\
& u_{i}=\left(\frac{\rho_{f} A_{f}}{E I}\right)^{\frac{1}{2}} L U_{i}, \quad u_{o}=\left(\frac{\rho_{f} A_{o}}{E I}\right)^{\frac{1}{2}} L U_{o}, \quad \beta_{o}=\frac{\rho_{f} A_{o}}{M_{p}+\rho_{f} A_{f}+\rho_{f} A_{o}}, \\
& \beta_{i}=\frac{\rho_{f}}{M_{p}+\rho_{f} A_{f}+\rho_{f} A_{o}}, \quad \gamma=\frac{\left(M_{p}+\rho_{f} A_{f}-\rho_{f} A_{o}\right) g L^{3}}{E I}, \quad \Gamma=\frac{\left.T\right|_{L} L^{2}}{E I}, \\
& \Pi_{i L}=\frac{\left.p_{i}\right|_{L} A_{f} L^{2}}{E I}, \quad \Pi_{o L}=\frac{\left.p_{o}\right|_{L} A_{o} L^{2}}{E I}, \quad c_{f}=\frac{4 C_{f}}{\pi}, \\
& \kappa_{u}=\frac{k_{u} L^{2}}{\left[E I\left(M_{p}+\rho_{f} A_{f}+\rho_{f} A_{o}\right)\right]^{\frac{1}{2}}}, \quad \varepsilon=\frac{L}{D_{o}}, \quad h=\frac{D_{o}}{D_{h}}, \\
& \alpha=\frac{D_{i}}{D_{o}}, \quad \alpha_{c h}=\frac{D_{c h}}{D_{o}}, \quad r_{a n n}=\frac{L_{s}}{L} .
\end{aligned}
$$

Thus, the resulting dimensionless form of Equation (36) is

$$
\begin{aligned}
& \frac{\partial^{4} \eta}{\partial \xi^{4}}+\left\{\gamma+\frac{1}{2} c_{f} \varepsilon u_{0}^{2}(h+1)\left[1-H\left(\xi-r_{a n n}\right)\right]-\frac{1}{2} u_{0}^{2}\left(1-K_{1}\right) \delta_{D}\left(\xi-r_{a n n}\right)\right\} \frac{\partial \eta}{\partial \xi} \\
& -\left\{\gamma(1-\tilde{\xi})+\frac{1}{2} c_{f} \varepsilon u_{o}^{2}(h+1)\left(r_{a n n}-\tilde{\xi}\right)\left[1-H\left(\xi-r_{a n n}\right)\right]-\frac{1}{2} u_{o}^{2}\left(1-K_{1}\right)\left[1-H\left(\xi-r_{a n n}\right)\right]+\left(\Gamma-\Pi_{\mathrm{iL}}+\Pi_{\mathrm{oL}}\right)\right\} \frac{\partial^{2} \eta}{\partial \xi^{2}} \\
& +\left\{u_{i}^{2}+\chi u_{o}^{2}\left[1-H\left(\xi-r_{a n n}\right)\right]\right\} \frac{\partial^{2} \eta}{\partial \xi^{2}}+\left\{1+(\chi-1) \beta_{0}\left[1-H\left(\xi-r_{a n n}\right)\right]\right\} \frac{\partial^{2} \eta}{\partial \tau^{2}}+2\left(\chi u_{o} \beta_{o}^{\frac{1}{2}}\left[1-H\left(\xi-r_{a n n}\right)\right]-u_{i} \beta_{i}^{\frac{1}{2}}\right) \frac{\partial^{2} w}{\partial \xi \partial \tau} \\
& \left.+\frac{1}{2} c_{f} \varepsilon u_{o} \beta_{0}^{\frac{1}{2}}\left[1-H\left(\xi-r_{a n n}\right)\right] \frac{\partial \eta}{\partial \tau}+\kappa_{u}\left\{1+\left[1-H\left(\xi-r_{a n n}\right)\right]\left(\frac{1+\alpha_{c h}-3}{\left(1-\alpha_{c h}-2\right.}\right)^{2}-1\right)\right\} \frac{\partial \eta}{\partial \tau}=0 \text {, }
\end{aligned}
$$


with corresponding dimensionless boundary conditions

$$
\eta(0, \tau)=\left.\frac{\partial \eta}{\partial \xi}\right|_{\xi=0}=0,\left.\frac{\partial^{2} \eta}{\partial \xi^{2}}\right|_{\xi=1}=\left.\frac{\partial^{3} \eta}{\partial \xi^{3}}\right|_{\xi=1}=0 .
$$

Additionally, the dimensionless (complex) frequency of vibration, $\omega$, is related to the dimensional one, $\Omega$, by

$$
\omega=\left[\frac{M_{p}+\rho_{f} A_{f}+\rho_{f} A_{o}}{E I}\right]^{\frac{1}{2}} L^{2} \Omega .
$$

It is noted that the external and internal fluid pressures in dimensionless form at the free end have the relationship

$$
\Pi_{i L}=\alpha^{2} \Pi_{o L}-\frac{1}{2} u_{i}^{2}-A_{f} \rho_{f} g h_{a}\left(\frac{L^{2}}{E I}\right)
$$

where

$$
\Pi_{o L}=\frac{1}{2} c_{f} h r_{a n n} \varepsilon u_{o}^{2}+\frac{1}{2} u_{o}^{2}\left(1-K_{1}\right)+\frac{A_{o} \rho_{f} g L^{3}}{E I},
$$

with $h_{a}$ given in Equation (37), and $K_{1}$ as shown in Equation (29).

Finally, the dimensionless flow velocities are expressed as

$$
u_{o}=\frac{\alpha}{\alpha_{c h}^{2}-1} u_{i}
$$

where $\alpha$ and $\alpha_{c h}$ are defined in (41).

\section{Solution of Equations by a Galerkin Method}

The governing Equation (42) of lateral vibration of the cantilever pipe contains the Heaviside step function, which is a discontinuous function, and a conventional Galerkin method is used here to discretize this system into an ordinary differential equation. The cantilever pipe is divided into $N$ units. Consequently, solution of Equation (42) was effected as follows. Let an approximate solution be

$$
\eta(\xi, \tau) \approx \widetilde{\eta}(\xi, \tau)=\sum_{j=1}^{N} \Phi_{j}(\xi) q_{j}(\tau) .
$$

In $(48), q_{j}(\tau)$ is the generalized coordinate of the system and written as

$$
q_{j}(\tau)=s_{j} e^{i \omega_{j} \tau}=\frac{s_{j}}{e^{\operatorname{Im}\left(\omega_{j}\right) \tau}} e^{i \operatorname{Re}\left(\omega_{j}\right) \tau} .
$$

The $\Phi_{j}(\xi)$ are the appropriate comparison functions, in this case the normalized beam eigenfunctions for the fixed-free E-B beam, and satisfy the geometric and natural boundary conditions of the problem. The $q_{j}(\tau)$ are the generalized coordinates of the system. In Equation (49), $\omega_{j}$ are the eigenfrequencies; $s_{j}$ is a complex amplitude; and $\operatorname{Im}\left(\omega_{j}\right)$ and $\operatorname{Re}\left(\omega_{j}\right)$ are the imaginary and real part of $\omega_{j}$, respectively. It is assumed that the solution of Equation (42) is separable in terms of the dimensionless spatial variable $\xi$ and the dimensionless time $\tau$.

Equation (48) denotes a truncated series, in which $N$ is finite positive integer and it represents the number of the appropriate comparison functions. For the sake of compactness of the notation, the following integral expressions are defined as

$$
\begin{array}{rlrl}
a_{i j_{(m, n)}} & \equiv \int_{m}^{n} \Phi_{i} \Phi_{j} d \xi, & b_{i j_{(m, n)}} \equiv \int_{m}^{n} \Phi_{i}\left(\frac{\partial \Phi_{j}}{\partial \xi}\right) d \xi, \\
c_{i j_{(m, n)}} \equiv \int_{m}^{n} \Phi_{i}\left(\frac{\partial^{2} \Phi_{j}}{\partial \xi^{2}}\right) d \xi, & d_{i j_{(m, n)}} \equiv \int_{m}^{n} \xi \Phi_{i}\left(\frac{\partial^{2} \Phi_{j}}{\partial \xi^{2}}\right) d \xi,
\end{array}
$$


where $i, j$ are indices corresponding to the relevant quantity to be integrated; $m$ and $n$ of $(m, n)$ are the lower/upper bounds of integration.

Substituting Equations (48) and (50) into (42), simultaneous equations of the form are obtained by pre-multiplying by $\Phi_{i}$ and integrating from $\xi=0$ to $\xi=1$

$$
\mathbf{M} \frac{\mathrm{d}^{2}}{\mathrm{~d} \tau^{2}}\left(\left\{\begin{array}{c}
q_{1} \\
q_{2} \\
\vdots \\
q_{3}
\end{array}\right\}\right)+\mathbf{C} \frac{\mathrm{d}}{\mathrm{d} \tau}\left(\left\{\begin{array}{c}
q_{1} \\
q_{2} \\
\vdots \\
q_{3}
\end{array}\right\}\right)+\mathbf{K}\left(\left\{\begin{array}{c}
q_{1} \\
q_{2} \\
\vdots \\
q_{3}
\end{array}\right\}\right)=0 .
$$

In Equation (51), M, C, and $\mathbf{K}$ matrices are mass matrix, damping matrix and stiffness matrix, respectively. The components of the $\mathbf{M}, \mathbf{C}$, and $\mathbf{K}$ matrices are

$$
\begin{aligned}
& \mathbf{M}_{i j}=a_{i j_{(0,1)}}-\beta_{o}(1-\chi) a_{i j_{(0, r a n n)}} \\
& \mathrm{C}_{i j}=-2 u_{i} \beta_{i}^{\frac{1}{2}} b_{i j_{(0,1)}}+2 \chi u_{o} \beta_{0}^{\frac{1}{2}} b_{i j_{(0, r a n n)}}+\frac{1}{2} c_{f} \varepsilon u_{o} \beta_{0}^{\frac{1}{2}} a_{i j_{(0, r a n n)}}+\kappa_{u} a_{i j_{(0,1)}}+\kappa_{u}\left(\frac{1+\alpha_{c h}-3}{\left(1-\alpha_{c h}-2\right)^{2}}-1\right) a_{i j(0, r a n n)},
\end{aligned}
$$

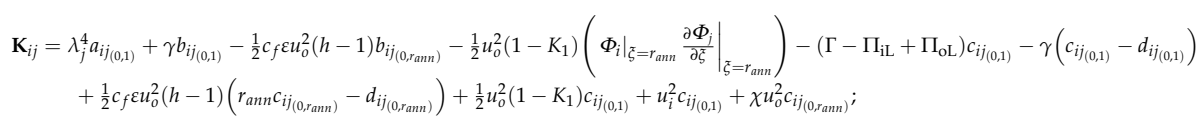

where $\lambda_{j}$ is the $j$ th dimensionless eigenvalue of the fixed-free $\mathrm{E}-\mathrm{B}$ beam.

Solutions of Equation (51) constitute approximate solutions of Equation (42) with boundary conditions in Equation (43). In order to obtain a non-trivial solution of Equation (51), it is required that the determinant of coefficient matrix is equal to zero. This corresponds to a generalized eigenvalue problem, and the stability of the system can be determined by the generalized eigenvalue (i.e., eigenfrequency) $\omega$ of matrix $\mathbf{E}$ which consists of $\mathbf{M}, \mathbf{C}$, and $\mathbf{K}$, as

$$
\mathbf{E}=\left[\begin{array}{cc}
-\mathbf{M}^{-1} \mathbf{C} & -\mathbf{M}^{-1} \mathbf{K} \\
\mathbf{I} & 0
\end{array}\right]
$$

For a given internal dimensionless flow velocity $u_{i}$, the stability of the cantilever pipe is determined by $\operatorname{Im}(\omega)$. When $\operatorname{Im}(\omega)<0$, the $q_{j}(\tau)$ (shown in Equation (49)) grows exponentially in time, so $\operatorname{Im}(\omega)<0$ indicates instability. Consequently, for $\operatorname{Im}(\omega)<0$ the cantilevered pipe becomes unstable, and for $\operatorname{Im}(\omega)=0$, divergence or buckling of the cantilever pipe happens. Divergence represents a static loss of stability, vulgarly known as buckling and, in the nonlinear dynamics milieu, as a static pitchfork bifurcation. In the following passages, any discussion of the system stability involves only the stability of the internal cantilevered pipe.

\section{Theoretical Analysis for Slender, Leaching-Tubing-Like Systems}

The geometry shown in Figure 1 has been applied in the salt cavern underground energy storage industry, called leaching-tubing systems. Salt caverns serving as underground energy storage are generally located at a depth between 500 and $2000 \mathrm{~m}$ [3], and storage volumes of salt caverns range from $5 \times 10^{4} \mathrm{~m}^{3}$ to $2 \times 10^{5} \mathrm{~m}^{3}[20,21]$. The typical depths of a salt cavern height and the salt cavern ceiling are about $400 \mathrm{~m}$ and $600 \mathrm{~m}$, respectively, learned from the industry survey described in [2]. Hence common lengths of the leaching tubing are on the order of one kilometer.

Based on information from industrial applications, theoretical analyses for slender leaching-tubing-like systems are carried out in this section. Sample dimensional and associated dimensionless parameters for the leaching tubing are given in Table 1. In the salt cavern storage industry, the geometric parameters $\alpha_{c h}, r_{a n n}$ and $L$ shown in Figure 1 can be varied by operators, as required by the engineering practice. Therefore, it is physically meaningful to discuss the effects of 
the geometric parameters $\alpha_{c h}, r_{a n n}$, and $L$ on the pipe system. The effects of varying $\alpha_{c h}, r_{a n n}$ and $L$ are discussed from Sections 4.1 to 4.3 .

Table 1. Sample properties of real-life leaching tubings and associated dimensionless parameters [1].

\begin{tabular}{ccccccccc}
\hline \multirow{2}{*}{$\begin{array}{c}\text { Dimensional } \\
\text { parameters }\end{array}$} & $D_{i}(\mathrm{~m})$ & $D_{o}(\mathrm{~m})$ & $D_{c h}(\mathrm{~m})$ & $L(\mathrm{~m})$ & $L_{s}(\mathrm{~m})$ & $E I\left(\mathrm{~N} \cdot \mathrm{m}^{2}\right)$ & $M_{p}(\mathrm{~kg} / \mathrm{m})$ & \\
\cline { 2 - 9 } & 0.159 & 0.1778 & 0.298 & 1283 & 1085 & $3.47 \times 10^{6}$ & 38.7 & \\
\hline $\begin{array}{c}\text { Dimensionless } \\
\text { parameters }\end{array}$ & $\alpha$ & $\alpha_{c h}$ & $\varepsilon$ & $\beta_{i}$ & $\beta_{o}$ & $h$ & $\gamma$ & $r_{\text {ann }}$ \\
\cline { 2 - 9 } & 0.897 & 1.676 & 7216 & 0.239 & 0.297 & 1.479 & $2.019 \times 10^{5}$ & 0.85 \\
\hline
\end{tabular}

\subsection{Effect of the Radial Confinement $\alpha_{c h}$}

Here, it is interesting to see the effect of different radial confinement values $\alpha_{c h}$ on the leaching-tubing-like system behavior. According to Equation (47), decreasing $\alpha_{c h}$ corresponds to an increase in radial confinement and to a related increase in the dimensionless annular flow velocity $u_{0}$.

The leaching-tubing-like systems behavior with the variation of $\alpha_{c h}$ from 1.10 to 20 is summarized in Table 2, based on $r_{a n n}=0.50$, and $\varepsilon=1124.9(L=200 \mathrm{~m})$ and the remaining parameters shown in Table 1. Theoretical results of both $u_{c r}$ and $\omega_{c r}$ are shown in Figure 6. $u_{c r}$ is a dimensionless critical instability flow velocity and indicates the onset of instability of the internal pipe. For example, Figure 7 shows the vibration and stability of the system with $\alpha_{c h}=1.20$, for the first three modes. From Figure 7 , we can see that when $u_{c r}=4.34$ the first predicted instability of the system occurs, and the associated frequency $\omega_{c r}=0$, which indicates the onset of divergence. Naturally, these results presented here are related to this particular parameters selection, and only indicate what the leaching-tubing-like systems behavior could be.

Table 2. Summary of the leaching-tubing-like systems behavior with the vibration of $\alpha$ ch from 1.10 to 20 .

\begin{tabular}{ccccccccccccc}
\hline & \multicolumn{1}{c}{ D1 } & F2 & F3 & \multicolumn{1}{c}{ F1 } & \multicolumn{4}{c}{ F2 } \\
Behavior $^{\mathbf{a}}$ & \multicolumn{1}{c}{} & & & & & & & \\
\hline$\alpha_{c h}$ & 1.10 & 1.20 & 1.27 & 1.32 & 1.35 & $\cdots$ & 4.46 & $\cdots$ & 20 & $\cdots$ \\
\hline
\end{tabular}

$\mathrm{F}$ and $\mathrm{D}$ represent two kinds of unstable modes, respectively, i.e., flutter instability and divergence. As an example, D1 denotes first-mode divergence and F1 denotes first-mode flutter. ${ }^{a}\left[r_{a n n}=0.50, \varepsilon=1124.9(L=200 \mathrm{~m})\right]$.

As shown in Table 2, when $\alpha_{c h} \approx 20$, i.e., the leaching-tubing-like system is effectively unconfined, flutter instability occurs in the second mode. For $1.35 \leq \alpha_{c h}<20$, the decrease in $\alpha_{c h}$ results in flutter instability in which the modes are sequentially lowered. However, for $1.32 \leq \alpha_{c h}<1.35$, flutter instability occurs in the third mode. A further decrease of $\alpha_{c h}$ below $\alpha_{c h}<1.32$ can still result in flutter instability in which the modes are sequentially lowered, until first-mode divergence (i.e., a static instability) arises for $1.10 \leq \alpha_{c h}<1.27$. The vanishing of $\operatorname{Re}(\omega)$ indicates the beginning of divergence, as clearly seen in Figure 6.

With regard to the dimensionless critical flow velocity $u_{c r}$, and with the very confined case $\left(\alpha_{c h}=1.10\right)$ as a reference, the increase of $\alpha_{c h}$ leads initially to the rapid increase of $u_{c r}$. This is followed by a steep and significant decrease of $u_{c r}$ as $\alpha_{c h}$ is increased continuously. Moreover, when $\alpha_{c h}>1.48$, $u_{c r}$ is less than 1.00. However, with a further increase of $\alpha_{c h}$ above $\alpha_{c h}>2.00$ approximately, $u_{c r}$ remains almost unaffected. As mentioned above, when $1.10 \leq \alpha_{c h}<1.27$, a first-mode divergence arises, so $\omega_{c r}$ is equal to 0 . An increase of $\alpha_{c h}$ to $1.27 \leq \alpha_{c h}<1.35$ causes a significant increase of $\omega_{c r}$. However, when $\alpha_{c h}>1.35$, decreased confinement causes a very steep reduction in $\omega_{c r}$. When $1.35 \leq \alpha_{c h}<4.46$, $\omega_{c r}$ remains almost unaffected with the increase of $\alpha_{c h}$. When $4.46 \leq \alpha_{c h}<20$, the system instability state changes from first-order flutter to second-order flutter, $\omega_{c r}$ steeply increases and remains almost unaffected with the increase of $\alpha_{c h}$. 


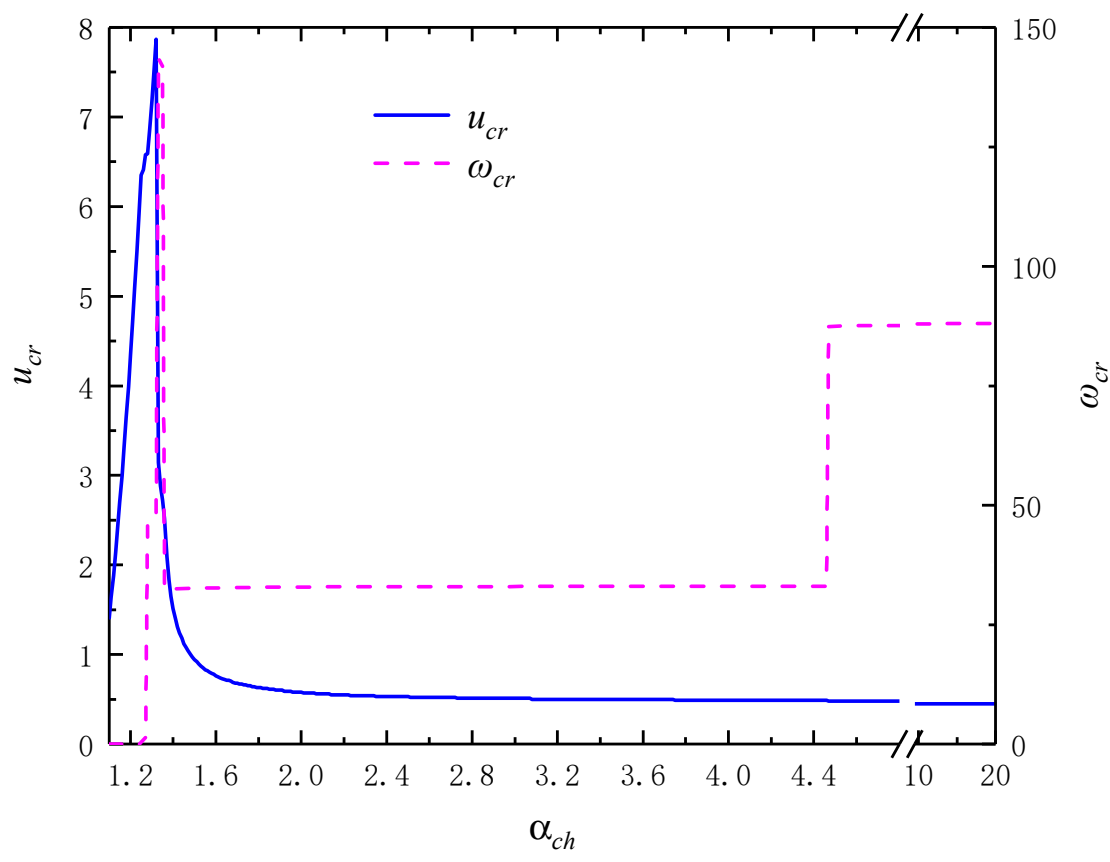

Figure 6. Leaching-tubing-like systems with $r_{a n n}=0.50$ and $\varepsilon=1124.9(L=200 \mathrm{~m})$, theoretical variation of $u_{c r}$ and $\omega_{c r}$ with the radial confinement $\alpha_{c h}$. The results are based on the instability of the first prediction. A zero frequency (i.e., $\omega_{c r}=0$ ) indicates divergence.

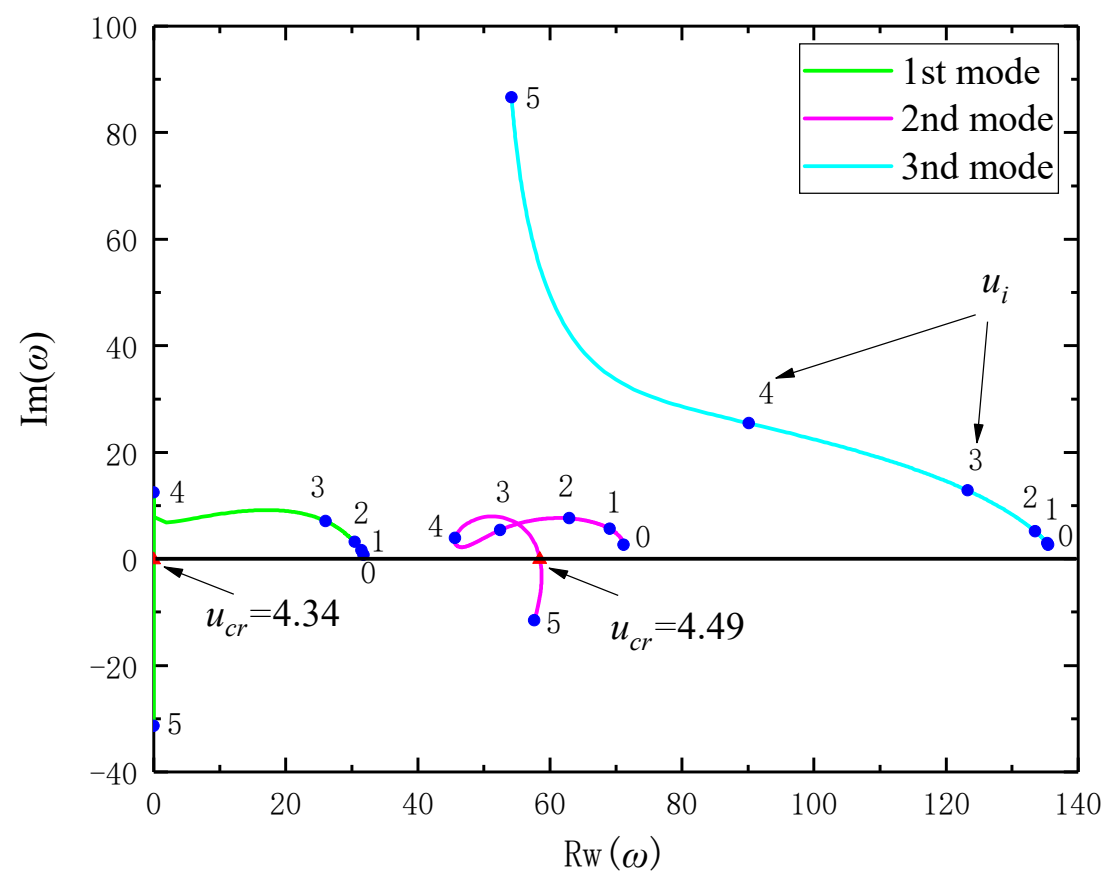

Figure 7. Argand diagram of the dimensionless complex eigenfrequencies of the leaching-tubing-like system, as a function of the nondimensional internal flow velocity $u_{i}$ for $\alpha_{c h}=1.20$. Blue solid circles represent the nondimensional internal flow velocity $u_{i}$. Red solid triangles represent the critical flow velocity when flutter instability occurs in the corresponding mode.

\subsection{Effect of the Confinement Length $r_{\text {ann }}$}

The effect of the confinement length $r_{a n n}$ (i.e., confined-flow length) on the slender leaching-tubing-like system is studied next. A larger value of the confinement length $r_{\text {ann }}$ corresponds to a larger part of the cantilevered pipe being subjected to annular flow. In the schematic view of the 
theoretical model shown in Figure 1, the inflexible external pipes cannot be longer than the internal cantilevered pipe. Consequently, the studied values of $r_{a n n}$ are less than 1 and the studied maximum value of $r_{a n n}$ is 0.9 .

The leaching-tubing-like systems behavior with the variation of $r_{\text {ann }}$ from 0 to 0.90 is summarized in Table 3, respectively based on $\alpha_{c h}=1.676, \varepsilon=562.5(L=100 \mathrm{~m})$ and $\alpha_{c h}=1.676, \varepsilon=1124.9(L=200 \mathrm{~m})$ and the remaining parameters shown in Table 1. Theoretical results of both $u_{c r}$ and $\omega_{c r}$ are shown in Figure 8. The value of $\alpha_{c h}=1.676$ is used, due to the typical degree of confinement in the real application. Here, two different leaching-tubing lengths (i.e., $L=100 \mathrm{~m}$ and $L=200 \mathrm{~m}$ ) are used to show the qualitative difference in system behavior.

Table 3. Summary of the leaching-tubing-like systems behavior with the vibration of $r_{a n n}$ from 0 to 0.90 .

\begin{tabular}{|c|c|c|c|c|c|c|c|c|c|c|}
\hline \multirow{2}{*}{$\begin{array}{c}\text { Behavior }^{\mathbf{a}} \\
r_{a n n}\end{array}$} & \multicolumn{5}{|c|}{ F1 } & \multicolumn{5}{|c|}{ F2 } \\
\hline & 0 & 0.15 & 0.30 & 0.45 & 0.60 & 0.72 & 0.75 & 0.80 & 0.85 & 0.90 \\
\hline Behavior ${ }^{b}$ & \multicolumn{2}{|c|}{ F2 } & \multicolumn{3}{|c|}{ F1 } & \multicolumn{5}{|c|}{ F2 } \\
\hline$r_{\text {ann }}$ & 0 & 0.15 & 0.19 & 0.45 & 0.60 & 0.69 & 0.75 & 0.80 & 0.85 & 0.90 \\
\hline
\end{tabular}

F represents a kind of unstable mode, i.e., flutter instability. As an example, F1 denotes first-mode flutter. ${ }^{\mathrm{a}}\left[\alpha_{c h}=1.676, \varepsilon=562.5(L=100 \mathrm{~m})\right] \cdot{ }^{\mathrm{b}}\left[\alpha_{c h}=1.676, \varepsilon=1124.9(L=200 \mathrm{~m})\right]$.
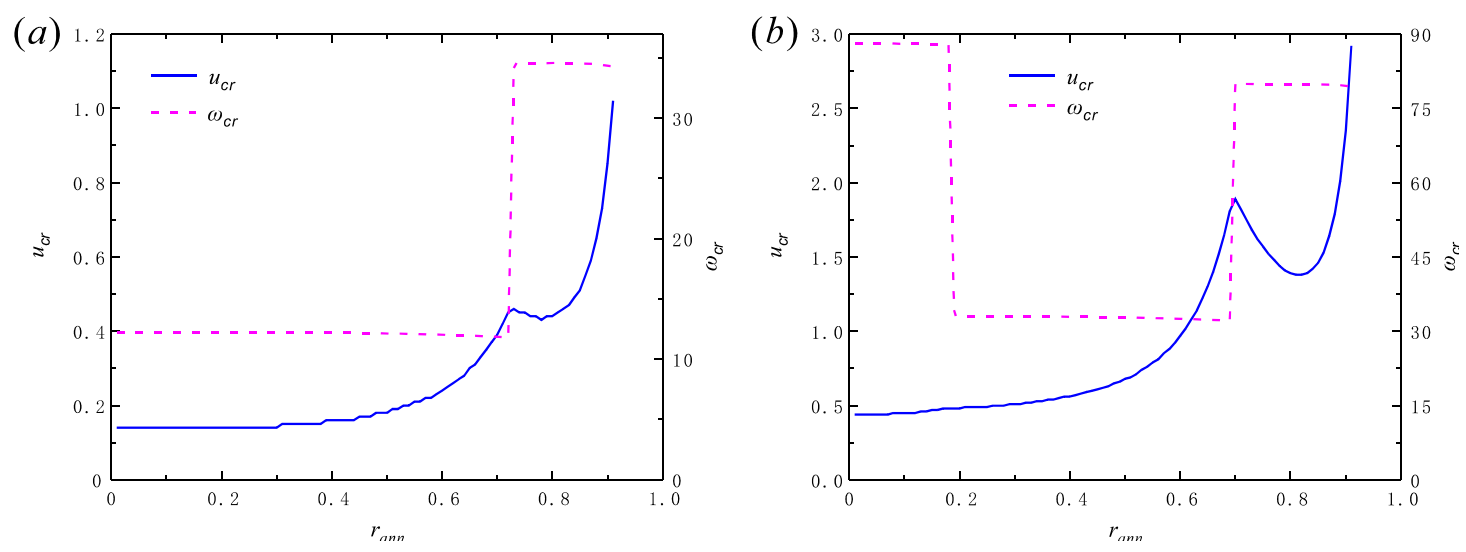

Figure 8. Leaching-tubing-like systems, theoretical variation of $u_{c r}$ and $\omega_{c r}$ with the confinement length $r_{a n n}$. The results are based on the instability of the first prediction. (a) Leaching-tubing with $\alpha_{c h}=1.676$ and $\varepsilon=562.5(L=100 \mathrm{~m})$. (b) Leaching-tubing with $\alpha_{c h}=1.676$ and $\varepsilon=1124.9(L=200 \mathrm{~m})$.

The slender leaching-tubing-like system behavior is discussed by considering $r_{a n n}$ values increased from $r_{a n n}=0$. For the shorter, $(L=100 \mathrm{~m})$ leaching-tubing-like system initially loses stability by the first-mode flutter. A further increase of $r_{a n n}$ results in the second-mode flutter. For the longer, ( $L=200 \mathrm{~m}$ ) leaching-tubing-like system, an increasing $r_{\text {ann }}$ leads initially to loss of stability by the second-mode flutter. A further increase of $r_{a n n}$ leads to first-mode flutter and second-mode flutter.

For the shorter leaching-tubing length considered, in terms of the dimensionless critical flow velocity $u_{c r}$, an increase of $r_{a n n}$ from 0 to 0.50 results in a slight stabilization. $u_{c r}$ increases nonlinearly with a further increase of $r_{a n n}$ from 0.50 to 0.72 . When $r_{a n n}$ increases from 0.72 to $0.90, u_{c r}$ begins to decrease and reaches a minimum at $r_{a n n}=0.78$, after which $u_{c r}$ continues to increase. As shown in Figure $8 \mathrm{a}, \omega_{c r}$ is almost unaffected by $r_{a n n}$ during the first-mode flutter phase and the second-mode flutter phase. However, when the unstable state changes from the first-mode flutter phase to the second-mode flutter phase, $\omega_{c r}$ increases steeply. For the longer leaching-tubing length considered, the dimensionless critical flow velocity $u_{c r}$ remains almost unaffected with the increase of $r_{a n n}$ from 
0 to 0.30 . Then, $u_{c r}$ increases nonlinearly with a further increase of $r_{a n n}$ from 0.30 to 0.69 . When $r_{a n n}$ increases from 0.69 to $0.90, u_{c r}$ begins to decrease and reaches a minimum at $r_{a n n}=0.81$, after which $u_{c r}$ continues to increase. As shown in Figure $8 \mathrm{~b}, \omega_{c r}$ is almost unaffected by $r_{a n n}$ during the first-mode flutter phase and the second-mode flutter phase. However, when the unstable state changes from the second-mode flutter phase to the first-mode flutter phase, $\omega_{c r}$ steeply decreases. When the unstable state returns from the first-mode flutter back to the second-mode flutter, $\omega_{c r}$ steeply increases. Hence, for both leaching-tubing lengths considered, the curve of $u_{c r}$ has a $\mathrm{U}$ shape, and the curve of $\omega_{c r}$ is stepped.

\subsection{Effect of the Cantilevered Pipe Length $L$}

Dimensional length $L$ of the cantilevered pipe has been used in the nondimensionalization of both the flow velocity $u_{i}$ and the frequency $\omega$. Consequently, the dimensionless parameters given in Equation (41) are unsuitable for studying the dependence of the dynamics on the system length. Another set of dimensionless parameters have been defined in [9] to study the dynamic characteristics of slender hanging pipes conveying fluid and in [22] to study the dynamic characteristics of cylinders in axial flow. In the present paper, no new dimensionless quantities have been defined, but rather the dimensional critical flow velocity $U_{c r}$ and associated frequency $\Omega_{c r}$ have been used to carried out a brief analysis. Notwithstanding the loss of generality, this approach facilitates illustrating the variation of the $U_{c r}$ and $\Omega_{c r}$ with increasing the pipe system length $L$. Based on diameters, mass, and stiffness typical of a leaching-tubing, as shown in Table 1, numerical results are obtained to predict dynamical behaviors of the leaching-tubing-like systems with increasing lengths $L$ for various values of $r_{\text {ann }}$.

As shown in Table 4, the leaching-tubing-like systems behavior with the variation of $L$ from $5 \mathrm{~m}$ to $500 \mathrm{~m}$ is summarized, based on $r_{a n n}=0.125,0.25,0.50$, and 0.85 . When $5 \mathrm{~m} \leq L \leq 500 \mathrm{~m}$, with increasing of the length, the leaching-tubing loses stability by first-mode flutter, for $r_{a n n}=0.125,0.25$, and 0.50 , while the leaching-tubing loses stability by second-mode flutter, for $r_{a n n}=0.85$. Theoretical results of both $U_{c r}$ and $\Omega_{c r}$ are shown in Figures 9 and 10. When the length $L$ is below $40 \mathrm{~m}$, an increasing of $L$ leads initially to a nearly negligible stabilization. After that, $U_{c r}$ increases significantly with a further increase of $L$ from $40 \mathrm{~m}$ to $500 \mathrm{~m}$. $U_{c r}$ increases approximately linearly, for $r_{a n n}=0.125,0.25$, and 0.50 , while $U_{c r}$ increases approximately nonlinearly, for $r_{a n n}=0.85$. For all studied values of $r_{a n n}$, with increasing the pipe system length $L$, the critical frequency $\Omega_{c r}$ decrease. Especially when $L<50 \mathrm{~m}$, $\Omega_{c r}$ decreases sharply. Moreover, for a long enough system, the frequency $\Omega_{c r}$ almost vanishes, which indicates a divergence is about to begin.

Table 4. Summary of the leaching-tubing-like systems behavior with increasing $L$ from 5 to $500 \mathrm{~m}$.

\begin{tabular}{|c|c|c|c|c|c|}
\hline Behavior $^{a, b}, c$ & & & F1 & & \\
\hline$L(\mathrm{~m})$ & 5 & 150 & 300 & 450 & 500 \\
\hline Behavior ${ }^{d}$ & & & F2 & & \\
\hline$L(\mathrm{~m})$ & 5 & 150 & 300 & 450 & 500 \\
\hline
\end{tabular}

${ }^{\mathrm{a}}\left[\alpha_{c h}=1.676, r_{a n n}=0.125\right],{ }^{\mathrm{b}}\left[\alpha_{c h}=1.676, r_{a n n}=0.25\right] .{ }^{\mathrm{c}}\left[\alpha_{c h}=1.676, r_{a n n}=0.50\right], \mathrm{d}\left[\alpha_{c h}=1.676, r_{a n n}=0.85\right]$. 

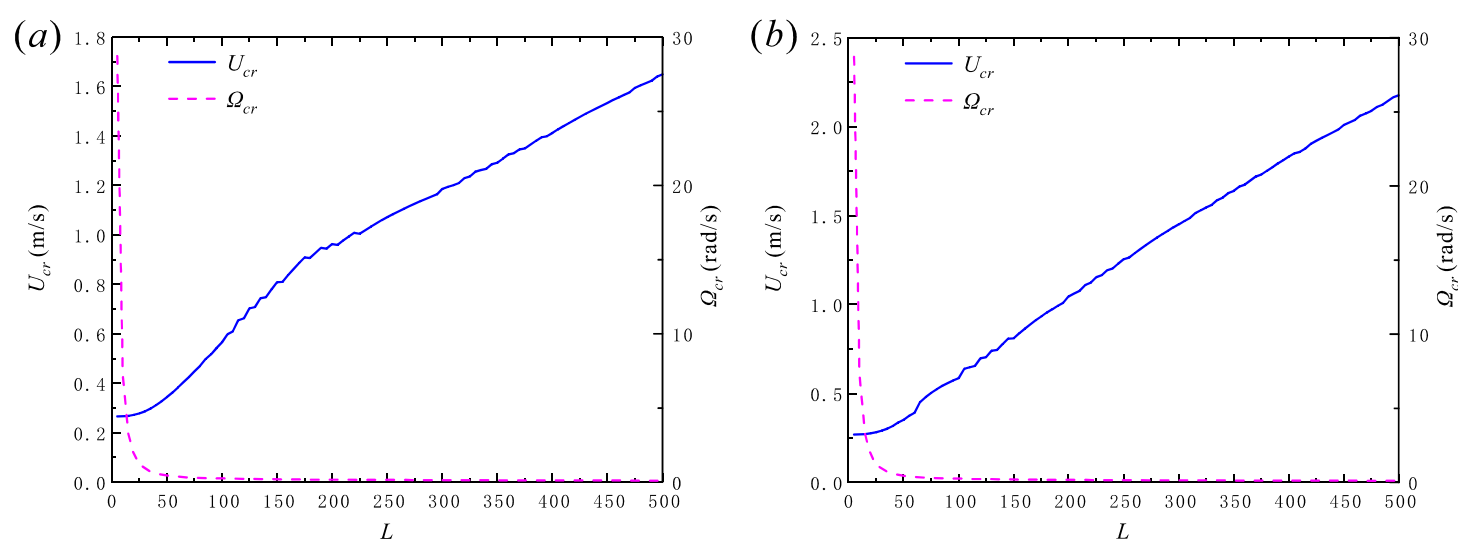

Figure 9. Leaching-tubing-like systems, theoretical variation of $U_{c r}$ and $\Omega_{c r}$ with the increase of the pipe system length $L$. The results are based on the instability of the first prediction. (a) Leaching-tubing with $\alpha_{c h}=1.676$ and $r_{a n n}=0.125$. (b) Leaching-tubing with $\alpha_{c h}=1.676$ and $r_{a n n}=0.25$.
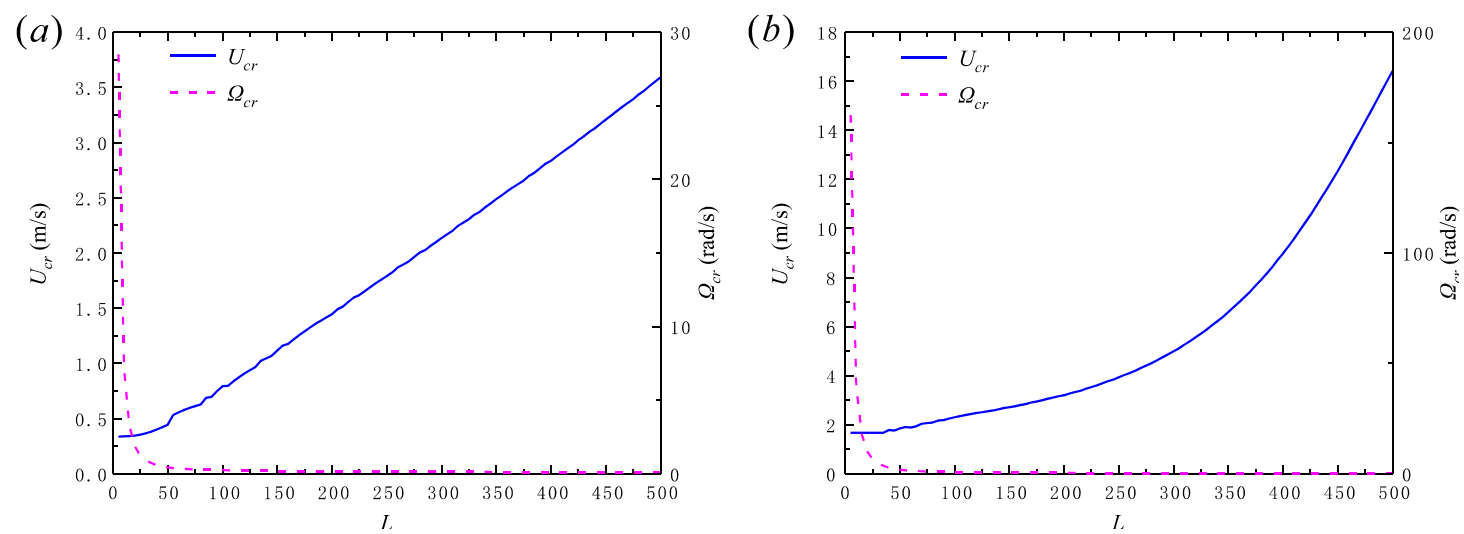

Figure 10. Leaching-tubing-like systems, theoretical variation of $U_{c r}$ and $\Omega_{c r}$ with the increase of the pipe system length $L$. The results are based on the instability of the first prediction. (a) Leaching-tubing with $\alpha_{c h}=1.676$ and $r_{a n n}=0.50$. (b) Leaching-tubing with $\alpha_{c h}=1.676$ and $r_{\text {ann }}=0.85$.

\section{Conclusions}

A linear theoretical model has been formulated for a hanging vertical cantilevered pipe which is subjected concurrently to two dependent axial flows. It should be pointed out that after the external flow exits from the outside annular passage, fluid is conveyed upwards as the internal flow in the cantilever pipe. The motion equation of the system is solved by means of a Galerkin method, and eigenfunctions of Euler-Bernoulli beam are used as comparison functions. Theoretical predictions were obtained for a long leaching-tubing-like system with parameters related to the salt cavern energy storage.

A theoretical study into the effect of radial confinement (i.e., the degree of radial confinement of the annular passage) has shown that, the system loses stability in flutter and even in divergence regardless of length, as the radial confinement degree and consequently the annular flow velocity is increased. When $\alpha_{c h}$ is greater than a certain value, $u_{c r}$ decreases as $\alpha_{c h}$ increases, even to a small value. Considering that the flow velocity in industrial applications is relatively large, the value of $\alpha_{c h}$ should not be too large. Additionally, only when values of $\alpha_{c h}$ exceed a certain parameter-dependent threshold does the radial confinement has no appreciable effect on the pipe system.

The confinement length $r_{a n n}$ (i.e., confined-flow length), was shown to have a destabilizing or stabilizing effect on the pipe system, depending on value ranges of $r_{a n n}$. The effect is a clear and significant stabilization, especially when the annular flow extends over most portion of the cantilevered pipe. 
Furthermore, investigations have been conducted in dimensional terms on the effect of the pipe system length $L$, for the leaching-tubing-like system. The pipe system length $L$ was shown to have a stabilizing effect on the pipe system. Increasing the pipe system length $L$ results in an increase of dimensional critical flow velocity $U_{c r}$, while it results in a decrease of the associated dimensional frequency $\Omega_{c r}$. For a long enough system, the frequency $\Omega_{c r}$ almost vanishes, which indicates a divergence is about to begin.

The next step is to conduct experiments to check the validity of the linear theoretical model, based on the device described in [23], and further research results are deferred to another paper.

Author Contributions: X.G. conceived the study, derived formulas, interpreted the results and wrote the paper under the guidance of Y.L. and C.Y. X.C. and N.Z. helped in the numerical calculation. X.S. and H.M. reviewed the study plan, edited the manuscript, and corrected the grammar mistakes. H.Y. participated in data analysis.

Funding: This research was funded by National Natural Science Foundation of China grant number 51874273, 51874274, 51774266 and by National Key Research and Development Program of China grant number 2018YFC0808401. And The APC was funded by 51874274.

Acknowledgments: The authors would like to be sincerely grateful to Jaak J.K. Daemen from University of Nevada, USA, for his English help and thoughtful review of this paper. The authors would like to gratefully acknowledge the financial support from National Natural Science Foundation of China (nos. 51874273, 51874274, 51774266), and the National Key Research and Development Program of China (grant no. 2018YFC0808401).

Conflicts of Interest: The authors declare no conflict of interest.

\section{References}

1. Moditis, K.; Païdoussis, M.P.; Ratigan, J. Dynamics of a partially confined, discharging, cantilever pipe with reverse external flow. J. Fluids Struct. 2016, 63, 120-139. [CrossRef]

2. Ratigan, J.L. Brine string integrity and model evaluation. In Proceedings of the Processes of SMRI Fall Meeting, Galveston, TX, USA, 13-14 October 2008; pp. 273-293.

3. Li, Y.; Yang, C.; Qu, D.; Yang, C.; Shi, X. Preliminary study of dynamic characteristics of tubing string for solution mining of oil/gas storage salt caverns. Rock Soil Mech. 2012, 33, 681-686.

4. Cesari, F.; Curioni, S. Buckling instability in tubes subject to internal and external axial fluid flow. In Proceedings of the 4th Conference on Dimensioning, Hungarian Academy of Science, Budapest, Hungary, October 1971; pp. 301-311.

5. Hannoyer, M.; Païdoussis, M.P. Instabilities of tubular beams simultaneously subjected to internal and external axial flows. J. Mech. Des. 1978, 100, 328-336. [CrossRef]

6. Paidoussis, M.P.; Besancon, P. Dynamics of arrays of cylinders with internal and external axial flow. J. Sound Vib. 1981, 76, 361-379. [CrossRef]

7. Wang, X.; Bloom, F. Dynamics of a submerged and inclined concentric pipe system with internal and external flows. J. Fluids Struct. 1999, 13, 443-460. [CrossRef]

8. Païdoussis, M.P.; Luu, T.; Prabhakar, S. Dynamics of a long tubular cantilever conveying fluid downwards, which then flows upwards around the cantilever as a confined annular flow. J. Fluids Struct. 2008, 24, 111-128. [CrossRef]

9. Doaré, O.; De Langre, E. The flow-induced instability of long hanging pipes. Eur. J. Mech. A. Solids 2002, 21, 857-867. [CrossRef]

10. Lemaitre, C.; Hémon, P.; De Langre, E. Instability of a long ribbon hanging in axial air flow. J. Fluids Struct. 2005, 20, 913-925. [CrossRef]

11. Kuiper, G.; Metrikine, A. Dynamic stability of a submerged, free-hanging riser conveying fluid. J. Sound Vib. 2005, 280, 1051-1065. [CrossRef]

12. Kuiper, G.; Metrikine, A. Experimental investigation of dynamic stability of a cantilever pipe aspirating fluid. J. Fluids Struct. 2008, 24, 541-558. [CrossRef]

13. Chen, S.; Wambsganss, M.T.; Jendrzejczyk, J. Added mass and damping of a vibrating rod in confined viscous fluids. J. Appl. Mech. 1976, 43, 325-329. [CrossRef]

14. Païdoussis, M.P. Fluid-Structure Interactions: Slender Structures and Axial Flow, 2nd ed.; Academic Press: Oxford, UK, 2014; Volume 1. 
15. Païdoussis, M.P. Fluid-Structure Interactions: Slender Structures and Axial Flow, 2nd ed.; Academic Press: Oxford, UK, 2016; Volume 2.

16. Lighthill, M. Note on the swimming of slender fish. J. Fluid Mech. 1960, 9, 305-317. [CrossRef]

17. Paidoussis, M.P. Dynamics of cylindrical structures subjected to axial flow. J. Sound Vib. 1973, 29, 365-385. [CrossRef]

18. Sinyavskii, V.; Fedotovskii, V.; Kukhtin, A. Oscillation of a cylinder in a viscous liquid. Sov. Appl. Mech. 1980, 16, 46-50. [CrossRef]

19. Brater, E.F.; King, H.W.; Lindell, J.E.; Wei, C.Y. Handbook of Hydraulics for the Solution of Hydraulic Engineering Problems; McGraw-Hill: Boston, MA, USA, 1996.

20. Liu, W.; Muhammad, N.; Chen, J.; Spiers, C.; Peach, C.; Deyi, J.; Li, Y. Investigation on the permeability characteristics of bedded salt rocks and the tightness of natural gas caverns in such formations. J. Nat. Gas Sci. Eng. 2016, 35, 468-482. [CrossRef]

21. Liu, W.; Chen, J.; Jiang, D.; Shi, X.; Li, Y.; Daemen, J.K.; Yang, C. Tightness and suitability evaluation of abandoned salt caverns served as hydrocarbon energies storage under adverse geological conditions (AGC). Appl. Energy 2016, 178, 703-720.

22. De Langre, E.; Paidoussis, M.; Doaré, O.; Modarres-Sadeghi, Y. Flutter of long flexible cylinders in axial flow. J. Fluid Mech. 2007, 571, 371-389. [CrossRef]

23. Ge, X.; Li, Y.; Shi, X.; Chen, X.; Ma, H.; Yang, C.; Shu, C.; Liu, Y. Experimental device for the study of liquid-solid coupled flutter instability of salt cavern leaching tubing. J. Nat. Gas Sci. Eng. 2019, in press. [CrossRef]

(C) 2019 by the authors. Licensee MDPI, Basel, Switzerland. This article is an open access article distributed under the terms and conditions of the Creative Commons Attribution (CC BY) license (http://creativecommons.org/licenses/by/4.0/). 